Editorial

\title{
Pensar/fazer como prática da liberdade: a terapia ocupacional e o centenário de Paulo Freire
}

\author{
Magno Nunes Farias ${ }^{a}$ (D), Roseli Esquerdo Lopes ${ }^{a}$ (D) \\ ${ }^{a}$ Universidade Federal de São Carlos - UFSCar, São Carlos, SP, Brasil.
}

Como citar: Farias, M. N., \& Lopes, R. E. (2021). Pensar/fazer como prática da liberdade: a terapia ocupacional e o centenário de Paulo Freire. Cadernos Brasileiros de Terapia Ocupacional, 29, e3027. https://doi.org/10.1590/2526-8910.ctoED292021

Paulo Reglus Neves Freire nasceu no Brasil, em Recife, Pernambuco, em 19 de setembro de 1921. O respeito, o diálogo, a democracia, a busca pela coerência, a dialética entre liberdade e autoridade atravessaram sua vida desde a infância (Freire, 1994), fincados como elementos basilares para sua apreensão do mundo, no seu quefazer transbordado na sua obra.

Em 2021, comemoramos o centenário do nascimento desse intelectual que atravessou fronteiras as mais diversas até a sua morte em 1997. Esses 100 anos firmam seu rico percurso de elaboraçôes teóricas e metodológicas acerca das relaçôes de opressão e das possibilidades de transformação social, que têm sido utilizadas historicamente por diversos campos do saber, inclusive na terapia ocupacional, em diferentes lugares do mundo.

Alguns trabalhos vêm apontando a utilização desse autor por terapeutas ocupacionais brasileiros desde os anos de 1970. Isso pode ser visto no relato da terapeuta ocupacional Maria Heloisa da Rocha Medeiros (Reis, 2017), que, iniciando sua carreira docente junto ao Curso de Terapia Ocupacional da Universidade Metodista de Piracicaba (São Paulo - Brasil), em 1977, organizando a disciplina Terapia Ocupacional Aplicada às Condiçóes Sociais, nos conta: "E aí montamos um curso, inventamos um curso de TO Social! Pegamos Paulo Freire, outros autores que discutiam a marginalidade social e o que era a marginalidade [...] no segundo semestre de 1977" (Reis, 2017, p. 300).

Medeiros conta que participou do I Seminário de Educação Brasileira da Universidade Estadual de Campinas (SP - Brasil), em 1978, evento aberto por Paulo Freire por telefone no exterior, uma vez que teve negada sua entrada no país para essa participação. Relata ainda os encontros com as obras do autor durante seu mestrado em Filosofia da Educação na Pontifícia Universidade Católica de Campinas, iniciado em 1979, onde os professores Moacir Gadotti e Carlos Brandão trabalhavam diretamente com Freire em suas disciplinas. "Naquela época o livro Pedagogia do Oprimido veio substituir o Evangelho [...], e inspirava a todos que lutavam contra a ditadura militar em que vivíamos" (M. H. R. Medeiros, comunicação pessoal, 2 de abril de 2021). Seu trabalho Reflexóes sobre as atividades expressivas para uma prática terapêutica ocupacional libertadora, no V Encontro Científico Paulista de Terapeutas Ocupacionais (Medeiros, 1979), inspirava-se em Paulo Freire, dentre outros autores, como Carl Rogers, para 
propor o uso da atividade mediado por uma perspectiva histórica, cultural e subjetiva, em contraposição a uma prática prescritiva e centrada apenas no saber técnico.

Nas lembranças da coautora deste editorial, em apresentação numa semana de estudantes da área na Faculdade de Medicina da Universidade de São Paulo, em 1978, Freire estava presente no relato da terapeuta ocupacional Léa Soares sobre sua experiência profissional na educação de jovens e adultos.

Portanto, é possível dizer que Paulo Freire era buscado como uma referência em um período marcado pela luta pelo fim da ditadura militar, em que se almejava a redemocratização da sociedade brasileira, tensionando a ampliação de direitos civis, políticos e sociais, demarcando para os terapeutas ocupacionais novas demandas, o que implicou processos de transformação da própria terapia ocupacional de então (Lopes, 2016). Grupos de profissionais interessados em produzir elaboraçóes críticas no/para o campo, problematizando o papel técnico-político profissional dentro da sociedade desigual, tinham em Freire um aporte importante, que se adensa com o retorno de Freire ao Brasil com a anistia política, em 1980.

Assim, profissionais vêm procurando desenhar uma práxis terapêutico-ocupacional tomando referenciais freireanos, ainda que de forma tímida na literatura acessada. Isso pode ser visto nas breves elaboraçóes de Toldrá (1986), descrevendo uma experiência na Favela da Vila Nogueira e São Quirino, em Campinas (SP), voltada à educação popular, em que, inclusive, Paulo Freire também trabalhou. A autora afirma a importância dos princípios de Freire para compreender a vida cotidiana dos sujeitos, com base no respeito e na proximidade, essencial à prática orientada para a transformação (Toldrá, 1986).

Adiante, estão as elaboraçôes de Barros (2004) e Barros et al. (2007) na entrada do século XXI, que, configurando a terapia ocupacional social, afirmam a adoção de pressupostos freireanos para pensar/fazer uma terapia ocupacional a partir da noção de processo, destacando dois elementos tomados do autor: conscientização e diálogo.

A conscientização ultrapassa o nível da tomada de consciência pelo desvelamento das razóes de ser de uma dada situação seguida por uma ação transformadora desta realidade que se projeta. Paulo Freire [...] náo dissocia ação técnica da ação política (Barros et al., 2007, p. 352).

Fora do Brasil, temos publicaçóes de autores estrangeiros, como a de Townsend (1996), que traz Freire para debater sobre empoderamento e uma prática que envolva a possibilidade e a filosofia da esperança. Nesse viés, Townsend (1997a, 1997b) referencia esse autor, ainda que de forma breve, para discutir uma terapia ocupacional domesticadora e/ou verdadeiramente libertadora, dentro dos processos de exclusão, interrogando o poder e o potencial transformativo da ocupação, se pautada pela democracia e relaçóes horizontais e colaborativas. VanLeit (1998), pontuando os conceitos de empoderamento e diálogo, relata um trabalho de ação social com adolescentes, afirmando que: "As ideias de Freire compartilham semelhanças com a filosofia da terapia ocupacional na medida em que ele enfatiza métodos ativos na aprendizagem e o envolvimento dos indivíduos na determinação de suas próprias necessidades e prioridades" (VanLeit, 1998, p. 34).

Dessa maneira, como colocam Farias \& Lopes (2020), Paulo Freire é um autor que vem sendo utilizado historicamente pela terapia ocupacional, cujos aportes teórico- 
metodológicos podem ajudar a consolidar, fortalecer e instrumentalizar o quefazer de terapeutas ocupacionais comprometidos com a prática da liberdade com dialogicidade, baseada no compromisso ético-político, na criticidade-problematização, na democratização e na rigorosidade técnico-científica.

Ainda que sejam diferentes as maneiras de apreender Paulo Freire naquilo que informa a práxis da terapia ocupacional, um ponto comum é que essa práxis se configure com criticidade frente à realidade deflagrada pela vulnerabilidade social, econômica e cultural, que perpassa os diferentes sujeitos da ação, sujeitos envoltos em opressóes cotidianas.

Paulo Freire traz elementos para a terapia ocupacional que não só se dão por meio das análises críticas que denunciam as mazelas do mundo, como também por meio de recursos, metodologias e estratégias para anunciar formas e possibilidades para sua superação, tendo em vista que é necessário superar uma posição apenas verbalista sobre as problemáticas, que se estacionam no "blábláblá", sendo urgente então mirar a ação concreta para a mudança em diálogo com a reflexão, a fim de tornar possível transposições de situaçóes-limites (Freire, 1987).

Sob o viés de Freire (1987), ações terapêutico-ocupacionais tornam-se espaços de mediação de uma leitura crítica do mundo, na busca de possibilidades de emancipação para problematizar as contradiçóes socioeconômicas e culturais que atravessam as vidas das pessoas, desnaturalizando realidades injustas, atrelando-as a movimentos de (re)invençóes e (re)criaçóes dos cotidianos, em que se questiona o porquê das coisas (Farias \& Lopes, 2020).

Dessa maneira, o processo terapêutico-ocupacional se consolida na perspectiva da possibilidade da libertação, tendo em vista que "[...] a libertação é possibilidade; não sina, nem destino, nem fado" (Freire, 2013, p. 50, grifo do autor). Trata-se de uma tarefa técnica e política para a anti-opressão, entre aquilo que envolve as questóes de classe, raça/etnia, gênero, sexualidade, território e qualquer outro processo de desumanização, como coloca Freire (2001).

Sublinha-se a importância de a obra de Freire não ser colocada como um conjunto estático, a-histórico e inquestionável, pelo contrário, trata-se de um autor que sempre afirmava a necessidade de se dialogar criticamente com suas ideias e proposiçóes: "[...] se você me seguir você me destrói. A melhor maneira de me entender é me reinventar e não tentar se adaptar a mim" (Freire, 2014, p. 27). Assim, é tarefa também entre nós, terapeutas ocupacionais, essa reinvenção, com base numa apreensão densa e historicamente situada, evitando sermos, como outros, "turistas freireanos" (Freire, 2001, p. 61).

Os processos de opressão com relação aos quais as elaborações de Freire vão de encontro são históricos. Freire (1980), em Educação como prática da liberdade, cuja primeira edição é de 1967, enfatiza essa questão tomando um contexto brasileiro atravessado por elementos como colonialismo, escravidão e autoritarismo que, continuamente, se moldam e também se conservam, como salta aos nossos olhos na conjuntura atual que enfrentamos.

Ademais, esse contexto, marcado fortemente pela ordem neoliberal e neoconservadora, somado às desigualdades deflagradas pela pandemia de CoVID-19, tem atingido tragicamente a população vulnerável, expondo-a a uma política necrófila- 
guiada pela pulsão de uma morte simbólica e material (Malfitano et al., 2020; Farias \& Leite Junior, 2021).

Vivemos, em uma leitura de Gramsci (2007, p. 184), os sintomas mórbidos, resultantes do "fato de que o velho morre e o novo náo pode nascer", trazendo as marcas do que Freire denomina como sociedade fechada; todavia, dada sua historicidade, Freire nos lembra continuamente que o futuro é problematizável e que a transformação é possível - a História nunca é, mas está sendo (Freire, 2013). Por isso, essa sociedade que insiste em se fechar para a construção de sujeitos com consciência livre e criativa, também tem suas rachaduras, que decorrem de rupturas que podem viabilizar caminhos para "[...] formas de vida altamente permeáveis, interrogadoras, inquietas e dialogais, em oposição às formas de vida 'mudas', quietas e discursivas, das fases rígidas e militarmente autoritárias" (Freire, 1980, p. 60).

Para nós, relembrar e comemorar o centenário de Paulo Freire é importante para reafirmar sua atualidade e pertinência para pensar/fazer uma terapia ocupacional como prática da liberdade, calcada na solidariedade enquanto ação coletiva e política, para que gestemos inéditos-viáveis.

Outono de 2021, no segundo ano da pandemia.

\section{Referências}

Barros, D. D., Lopes, R. E., \& Galheigo, S. M. (2007). Terapia ocupacional social: concepções e perspectivas. In A. Cavalcanti \& C. R. C. Galvão (Eds.), Terapia ocupacional: fundamentação \& prática (pp. 347-353). Rio de Janeiro: Guanabara Koogan.

Barros, D. D. (2004). Terapia ocupacional social: o caminho se faz ao caminhar. Revista de Terapia Ocupacional da Universidade de São Paulo, 15(3), 90-97. http://dx.doi.org/10.11606/issn.22386149.v15i3p90-97.

Farias, M. N., \& Leite Junior, J. D. (2021). Vulnerabilidade social e Covid-19: consideraçóes com base na terapia ocupacional social. Cadernos Brasileiros de Terapia Ocupacional, 29, e2099. http://dx.doi.org/10.1590/2526-8910.ctoen2099.

Farias, M. N., \& Lopes, R. E. (2020). Terapia ocupacional social: formulaçóes à luz de referenciais freireanos. Cadernos Brasileiros de Terapia Ocupacional, 28(4), 1346-1356. http://dx.doi.org/10.4322/2526-8910.ctoEN1970.

Freire, P. (1980). Educação como prática da liberdade. São Paulo: Paz e Terra.

Freire, P. (1987). Pedagogia do oprimido. Rio de Janeiro: Paz e Terra.

Freire, P. (1994). Cartas a Cristina: reflexóes sobre minha vida e minha práxis. Rio de Janeiro: Paz e Terra.

Freire, P. (2001). Pedagogia dos sonhos possiveis. São Paulo: Editora UNESP.

Freire, P. (2013). À sombra desta mangueira. Rio de Janeiro: Paz e Terra.

Freire, P. (2014). Pedagogia da solidariedade. São Paulo: Paz e Terra.

Gramsci, A. (2007). Cadernos do cárcere. Rio de Janeiro: Civilização Brasileira.

Lopes, R. (2016). Cidadania, direitos e terapia ocupacional. In R. E. Lopes \& A. P. S. Malfitano (Eds.), Terapia ocupacional social: desenhos teóricos e contornos práticos (pp. 29-48). São Carlos: EdUFSCar.

Malfitano, A. P. S., Cruz, D. M. C., \& Lopes, R. E. (2020). Terapia ocupacional em tempos de pandemia: seguridade social e garantias de um cotidiano possível para todos. Cadernos Brasileiros de Terapia Ocupacional, 28(2), 401-404. http://dx.doi.org/10.4322/2526-8910.ctoED22802.

Medeiros, H. R. M. (1979). Reflexões sobre as atividades expressivas para uma prática terapêutica ocupacional libertadora. In Anais do $5^{\circ}$ Encontro Cientifico Paulista de Terapeutas Ocupacionais (pp. 35-48). São Paulo: Associação Paulista de Terapeutas Ocupacionais. 
Reis, S. C. C. A. G. (2017). Histórias e memórias da institucionalização acadêmica da terapia ocupacional no Brasil: de meados da década de 1950 a 1983 (Dissertação de mestrado). Universidade Federal de São Carlos, São Paulo.

Toldrá, R. C. (1986). Terapia ocupacional e educaçáo popular. In P. Freire, A. Nogueira \& D. Mazza (Eds.), Fazer escola conhecendo à vida (pp.83-88). São Paulo: Editora Papirus.

Townsend, E. (1996). Institutional ethnography: a method for showing how the context shapes practice. The Occupational Therapy Journal of Research, 16(3), 179-199. http://dx.doi.org/10.1177/153944929601600303.

Townsend, E. (1997a). Occupation: potential for personal and social transformation. Journal of Occupational Science, 4(1), 18-26. http://dx.doi.org/10.1080/14427591.1997.9686417.

Townsend, E. (1997b). Inclusiveness: a community dimension of spirituality. Canadian Journal of Occupational Therapy, 64(3), 146-155. http://dx.doi.org/10.1177/000841749706400311.

VanLeit, B. (1998). Adolescent social action program: involvement of occupational therapy students in an innovative health promotion program. Occupational Therapy in Health Care, 11(3), 29-37. PMid:23948044. http://dx.doi.org/10.1080/J003v11n03_03. 